Intecoms: Journal of Information Technology and Computer Science

Volume 2 Nomor 1, Juni 2019

e-ISSN : 2614-1574

p-ISSN : 2621-3249

DOI : https://doi.org/10.31539/intecoms.v2i1.629

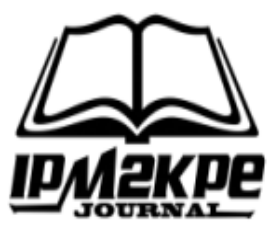

\title{
SISTEM INFORMASI PEMASARAN BUSANA SYAR'I DENGAN PENERAPAN CUSTOMER RELATIONSHIP MANAGEMENT (CRM) BERBASIS WEB
}

\section{SYAR'I FASHION MARKETING INFORMATION SYSTEM USING WEB-BASED CUSTOMER RELATIONSHIP MANAGEMENT (CRM)}

\author{
Yuda Irawan \\ STMIK Hang Tuah Pekanbaru \\ yudairawan89@gmail.com
}

\begin{abstract}
Toko Cahaya Sunnah is a business that produces and sells syar'i clothing. In its business development, Toko Cahaya Sunnah keep trying to expand its market target to out of town even all of Indonesia. To achieve its goal, Toko Cahaya Sunnah requires website. Currently in Toko Cahaya Sunnah in making sales report is still manual using excel application so that data processing of sales report still running slow and not yet detailed. Currently Toko Cahaya Sunnah does not have any special activities or strategies that handle marketing, product marketing is done in a conventional manner by providing customers with information about places, features and products to other potential customers. Ineffective information dissemination prevents customers from knowing the latest information in the Sunnah Light Store thus affecting customers to switch to other stores. With the website using the method of Customer Relationship Management (CRM) then the data storage process can be more accurate and stored neatly and making sales reports will be fast and timely and delivery of promotional information will be faster and response to sales will be faster.
\end{abstract}

Keywords: Information System, Customer Relationship Management (CRM), Web

\begin{abstract}
ABSTRAK
Toko Cahaya Sunnah merupakan usaha bisnis yang memproduksi dan menjual busana syar'i. Dalam pengembangan bisnisnya, Toko Cahaya Sunnah terus berusaha untuk memperluas target pasarnya sampai luar kota bahkan seluruh Indonesia. Untuk mencapai tujuannya, Toko Cahaya Sunnah memerlukan website. Saat ini di Toko Cahaya Sunnah dalam pembuatan laporan penjualan masih manual menggunakan aplikasi excel sehingga pengolahan data laporan penjualan masih berjalan lambat dan belum terperinci. Saat ini Toko Cahaya Sunnah tidak memiliki aktifitas atau strategi khusus yang menangani pemasaran, pemasaran produk dilakukan secara konvensional dengan cara pelanggan memberikan informasi mengenai tempat, keistimewaan dan produk ke calon pelanggan lain. Penyebaran informasi yang tidak efektif membuat pelanggan tidak mengetahui informasi terbaru pada Toko Cahaya Sunnah sehingga mempengaruhi pelanggan untuk beralih ke toko lain. Dengan adanya website menggunakan metode Customer Relationship Management (CRM) maka proses penyimpanan data dapat lebih akurat dan tersimpan rapi dan pembuatan laporan penjualan akan cepat dan tepat waktu serta penyampaian informasi promosi akan lebih cepat dan respon terhadap penjualan pun akan lebih cepat.
\end{abstract}

Kata Kunci : Sistem informasi, Customer Relationship Management (CRM), Web

\section{PENDAHULUAN}

Toko Cahaya Sunnah merupakan usaha bisnis yang memproduksi dan menjual busana syar'i. Dalam pengembangan bisnisnya, Toko Cahaya Sunnah terus berusaha untuk memperluas target pasarnya sampai luar kota bahkan seluruh Indonesia. Untuk mencapai tujuannya, Toko Cahaya Sunnah memerlukan website yang dapat menghubungkan penjual dan pembeli yang berbeda tempat dan tidak akan 
menjadi kendala dalam melakukan transaksi. Dengan adanya website calon pembeli dapat mengetahui informasi mengenai Produk yang dijual pada Toko Cahaya Sunnah dan Pemasaran melalui website sebuah perusahaan dapat memiliki sebuah pasar internasional.

Berdasarkan hasil wawancara dengan pemilik Toko Cahaya Sunnah ditemukan beberapa kendala diantaranya dalam pembuatan laporan penjualan masih manual menggunakan aplikasi excel sehingga pengolahan data laporan penjualan masih berjalan lambat dan belum terperinci. Saat ini Toko Cahaya Sunnah tidak memiliki aktifitas atau strategi khusus yang menangani pemasaran, pemasaran produk dilakukan secara konvensional dengan cara pelanggan memberikan informasi mengenai tempat, keistimewaan dan produk ke calon pelanggan lain. Penyebaran informasi yang tidak efektif membuat pelanggan tidak mengetahui informasi terbaru pada Toko Cahaya Sunnah sehingga mempengaruhi pelanggan untuk beralih ke toko lain.

Sistem pemasaran yang telah dijelaskan sebelumnya menyebabkan pemilik usaha harus berlomba dengan pesaingnya untuk mendapatkan pelanggan baru sebanyak-banyaknya dan mempertahankan pelanggan lama dengan menjalin komunikasi yang baik (Sugesti, 2018). Selain itu, semakin berkembangnya usaha busana syar'i membuat tingkat persaingannya menjadi lebih tinggi sehingga membuat pemilik usaha Toko Cahaya Sunnah harus mencari strategi bisnis yang tepat dalam menghadapi persaingan bisnis ini agar dapat mempertahankan pelanggannya dan meningkatkan penjualannya.Pelanggan yang loyal merupakan cermin dari kepuasan pelanggan, dimana pada saat ini harga tidak menjadi faktor yang utama bagimereka, namun menjadi sesuatu yang relatif.

Oleh karena itu, seiring berkembangnya teknologi informasi, maka perlu diterapkan suatu strategi yang lebih baik dengan cara mengimplementasikan suatu produk teknologi komunikasi informasi yang dapat membantu usaha ini menjadi lebih efektif dalam meningkatkan layanan marketing dan customer support, serta dapat menunjang pengambilan keputusan yang lebih baik bagi pemilik usaha. Penggunaan teknologi sangat membantu dalam mempertmudah dan mempercepat melakukan suatu aktivitas seperti pada penelitian terdahulu membuat sistem informasi perpustakaan pada persekolahan, sistem informasi penjualan berbasis kinerja (Hendrianto, 2014; Aisyah \& Falgenti, 2017).

Salah satu keunggulan dalam peningkatan layanan adalah dengan penerapan konsep Manajemen Hubungan Pelanggan atau Customer Relationship Management (CRM) (Bayu, 2017). Penggunaan Metode ini dalam pembangunan aplikasi telah di implemetasikan pada peneliti terdahulu dengan objek yang berbeda seperti Geovrisco (2012) pada sebuah koperasi di Sumatera Barat. CRM merupakan bisnis yang menggambarkan suatu strategi penempatan client sebagai pusat proses, aktivitas dan budaya. Konsep ini telah dikenal dan banyak diterapkan untuk meningkatkan pelayanan di perusahaan.

\section{METODE PENELITAN}

Metode yang penulis gunakan adalah metode waterfall. Secara garis besar metode waterfall mempunyai langkah sebagai berikut: analisa, desain, penulisan, pengujian dan penerapan serta pemeliharaan (Pressman, 2010). 


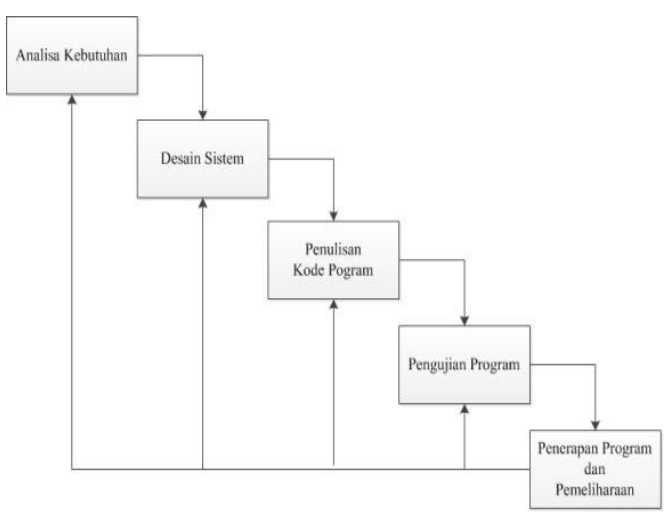

Gambar 1.Waterfall Model (Pressman, 2010)

Berikut adalah penjelasan dari tahapan yang dilakukan di dalam model waterfall:

Analisa Kebutuhan. Pada tahap pertama peneliti melakukan analisa terhadap kebutuhan aplikasi dan melakukan tahap pengumpulan data dengan melakukan pertemuan dengan pimpinan Toko Cahaya Sunnah yaitu bapak Wira Pada tahap ini juga dilakukan proses wawancara tentang masalah sistem yang sedang berjalan dan kebutuhan dari sistem informasi.

Desain Sistem. Pada tahap kedua ini desain dikerjakan setelah kebutuhan dari sistem informasi selesai dikumpulkan secara lengkap, kemudian perancangan sistem dengan menggunakan perangkat pemodelan sistem seperti use case diagram dan activity diagram, class diagram dan perancangan database, tabel dan fungsinya.

Penulisan Kode Program. Pada tahap ketiga desain program diterjemahkan ke dalam kode-kode dengan menggunakan bahasa pemrograman PHP dan MySQL sebagai web server-nya. Program yang dibangun langsung diuji baik secara unit (Madcoms, 2015).

Pengujian Program. Pada tahapan ini sistem yang baru diuji kemampuan dan keefektifannya sehingga didapatkan kekurangan dan kelemahan sistem yang kemudian dilakukan pengkajian ulang dan perbaikan terhadap aplikasi menjadi lebih baik dan sempurna.

Penerapan Program dan. Pemeliharaan.Ini merupakan tahap terakhir dalam model waterfall. Software sudah dijalankan serta dilakukan pemeliharaan. Pemeliharaan termasuk memperbaiki kesalahan yang tidak ditemukan pada langkah sebelumnya. Perbaikan implementasi unit sistem dan peningkatan jasa sistem sebagai kebutuhan baru.Seiring berkembangnya tekonologi perangkat lunak yang sudah diterapkan akan mengalami perubahan. Perubahan tersebut bisa karena mengalami kesalahan dan perkembangan zaman. Maka, untuk memperbaikinya perangkat lunak harus bisa menyesuaikan dengan lingkungan sistem operasi baru.

Dalam proses penyelesaian penelitian ini penulis menggunakan teknik pengumpulan data sebagai berikut :

Pengamatan langsung (observasi), yaitu suatu teknik pengumpulan data dengan cara melakukan pengamatan langsung pada Toko Cahaya Sunnah Pekanbaru untuk mengetahui bagaimana cara kerja sistem yang sedang berjalan, sehingga mendapatkan informasi untuk melakukan penerapan sistem informasi pemasaran busana syar'i dengan penerapan Customer Relationship Management (CRM) berbasis web.

Wawancara, yaitu metode pengumpulan data dengan cara berkomunikasi secara langsung dengan sumber data dan melakukan proses tanya jawab terhadap Bapak Wira selaku pemipin cahaya sunnah.

Studi pustaka, yaitu dengan mempelajari buku-buku, jurnal dan referensi yang berkaitan dengan penelitian ini. 


\section{Use Case Diagram}

Use case diagram dari sistem ini dapat dilihat pada gambar berikut:

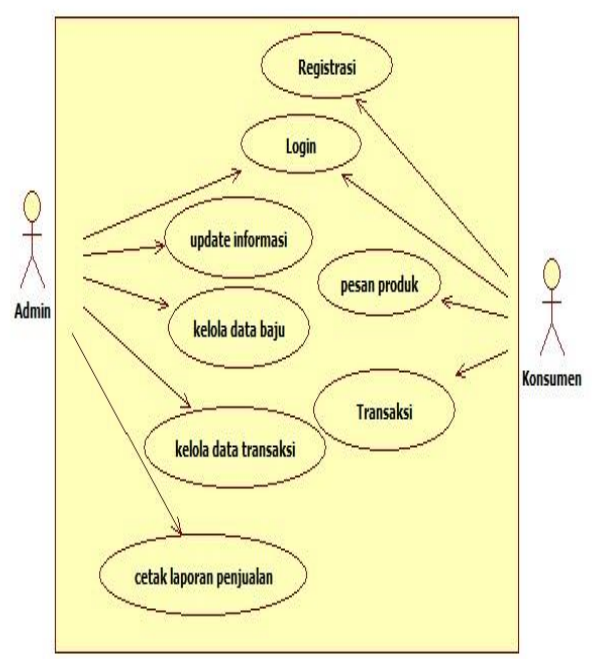

Gambar. 2 Use Case Diagram

\section{Class Diagram}

Pada gambar dibawah ini terdapat databasetokoCahaya Sunnah Pekanbaru dipaparkan hubungan antar atribut oleh masing - masing entitas pada sistem ini sehingga terlihat hubungan antara atributnya. Dapat dilihat pada gambar desain struktur database Class Diagram diatas menjelaskan hubungan antar class dan query tabel dari basis data sistem Cahaya Sunnah Pekanbaru.

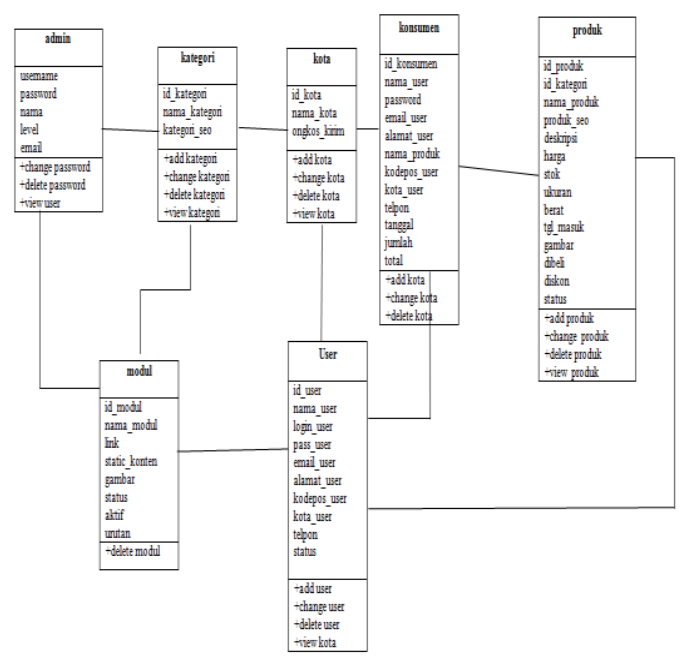

Gambar. 3 Class Diagram

\section{Activity Diagram}

Diagram activity menggambarkan bagaimana masing-masing alur berawal, diagram activity aplikasi sistem jual beli online dan pemasaran berbasis web .

\section{Diagram Activity Registrasi}

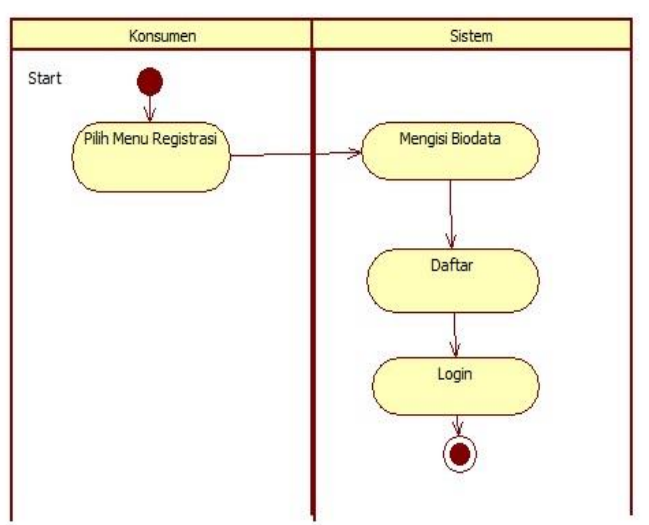

Gambar. 4 Diagram Activity Registrasi

Diagram aktivitas Pemesanan Produk ini terdapat satu actor yaitu Konsumen sebagai user.

\section{Diagram Activity Pesan Produk}

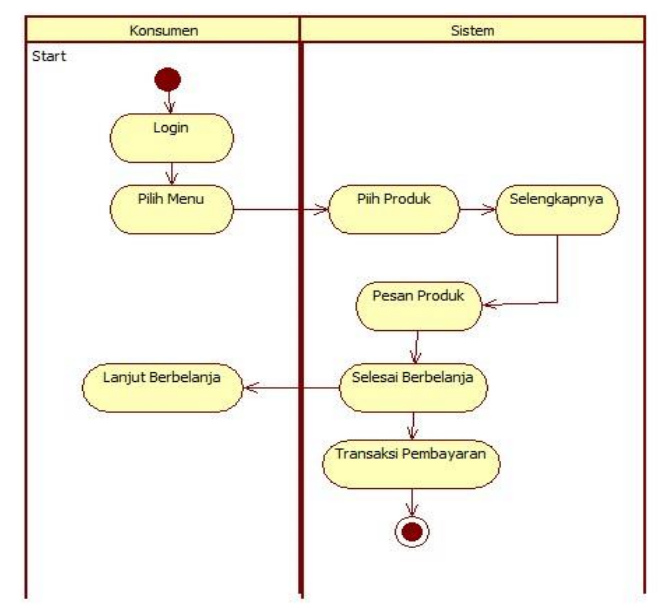

Gambar 5. Diagram Activity Pesan Produk

Langsung berada pada menu pesan produk, ketika sudah melakukan pemesanan produk maka konsumen melakukan transaksi pembayaran. 


\section{HASIL DAN PEMBAHASAN Halaman Utama}

Pada tampilan menu data produk terlihat gambar produk yang siap di order.Pada produk tersebut sudah tertera nama gamis, harga normal dan diskon serta tombol beli.

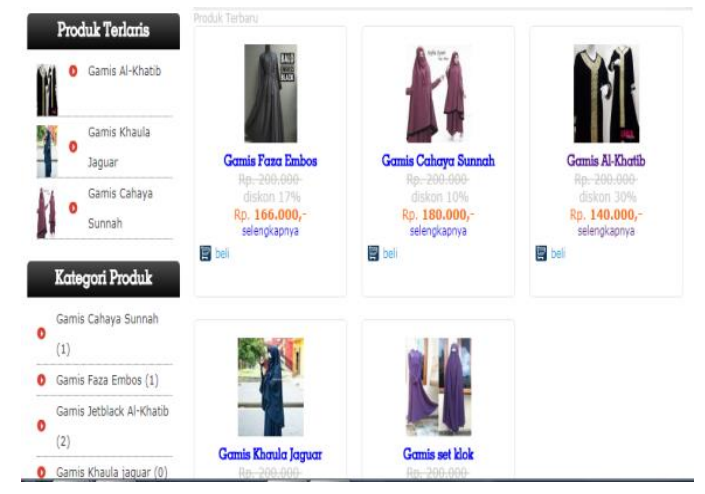

Gambar. 6 Halaman Utama

\section{Halaman Registrasi}

Pada tampilan menu registrasi ini dharuskan kepada konsumen untuk mengisi biodata sebelum login.Berikut adalah tampilan menu registrasi konsumen.

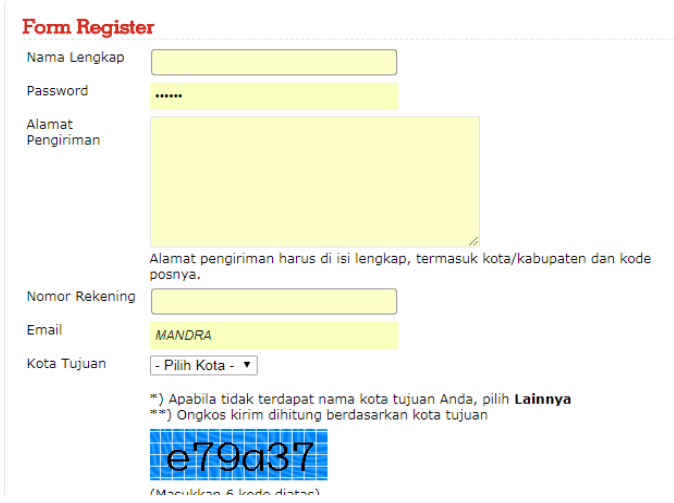

Gambar . 7 Halaman Registrasi

Pada tampilan menu registrasi di atas terlihat beberapa item yang wajib diisi oleh konsumen yang terdiri dari nama lengkap yang harus diisi sesuai Kartu Tanda Penduduk (KTP) konsumen, password diisi minimal dan maksimal 6 karakter, alamat sesuai Kartu Tanda Penduduk dan Kartu Keluarga (KTP/KK), nomor rekening harus yang aktif, email, kota tujuan, masukan kode yang sudah tertera di tampilan registrasi kemudian daftar.

\section{Halaman Menu Login Konsumen}

Pada tampilan menu login ini hanya konsumen yang bisa login dengan mengisi email dan password yang sesuai. Berikut adalah tampilan menu login konsumen.

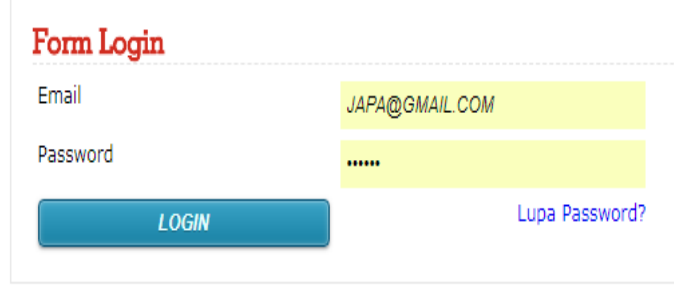

Gambar. 8 Halaman Menu Login Konsumen

Pada tampilan menu login konsumen di atas terlihat 2 item yang wajib diisi oleh konsumen agar bisa login ke menu data produk yaitu konsumen harus mengisi email dan password yang sudah dibuat di menu registrasi sebelumnya.

\section{Tampilan Menu Data Produk}

Tampilan menu data produk disaat konsumen sudah login dan ingin berbelanja.Berikut adalah tampilan menu data produk.

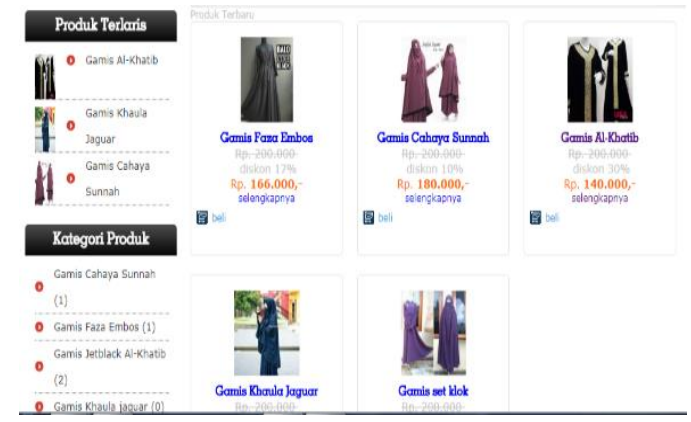

Gambar . 9 Tampilan Menu Data Produk

Pada tampilan menu data produk terlihat gambar produk yang siap di order konsumen stelah login, pada produk tersebut sudah tertera nama gamis, harga normal dan diskon serta tombol beli. 


\section{Keranjang Belanja}

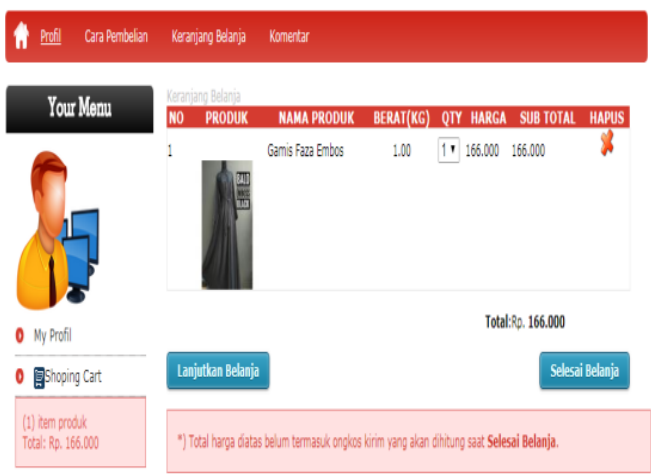

Gambar 10. Halaman Keranjang Belanja Pada tampilan menu selesai berbelanja telihat 2 gambar dimana pada gambar pertama merupakan tampilan disaat konsumen sudah menekan tombol beli produk, terdapat dua tombol pilihan untuk konsumen yaitu tombol lanjut berbelanja dan selesai berbelanja, jika konsumen pilih tombol lanjut berbelanja, maka konsumen akan kembali ke menu data produk dan jika konsumen pilih tombol selesai berbelanja maka konsumen agar melakukan pembayaran transaksi yang cara pembayarannya terlihat pada gambar info rekening toko.

\section{Tampilan Menu Login Admin}

Pada tampilan menu login admin ini hanya admin yang hanya bisa login dengan mengisi username dan password.Berikut adalah tampilan menu login admin.

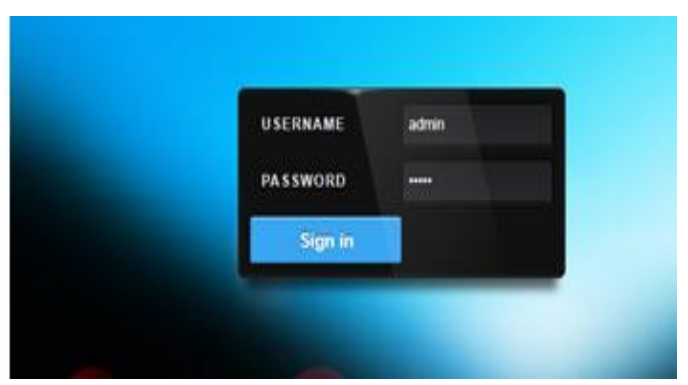

Gambar. 11 Tampilan Menu Login Admin

Pada penjelasan gambar pada tampilan menu login admin di atas terlihat dua item yang wajib diisi oleh admin agar bisa login ke menu home admin yaitu admin harus mengisi username dan password.

\section{Halaman Menu Admin}

Berikut adalah tampilan menu home admin.

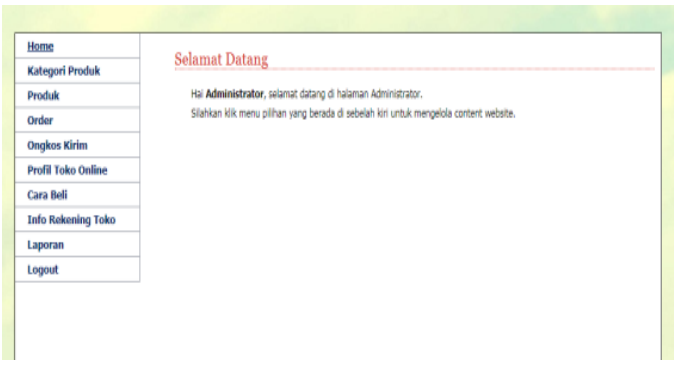

\section{Gambar. 12 Tampilan Menu Home}

Pada tampilan menu home konsumen di atas terlihat beberapa item yang akan diisi oleh admin yaitu kategori produk, produk, order, ongkos kirim, profil toko online, cara beli, info rekening toko, laporan, logout.

\section{Tampilan Menu Data Kategori Produk}

Berikut adalah tampilan form data kategori produk.

\begin{tabular}{|c|c|c|c|}
\hline Home & \multirow{2}{*}{\multicolumn{3}{|c|}{ Kategori }} \\
\hline Kategori Produk & & & \\
\hline Produk & \multicolumn{3}{|c|}{ Tambah Kategori } \\
\hline Order & \multicolumn{2}{|c|}{ NO NAMA KATEGORI } & AKSI \\
\hline Ongkos Kirim & 1 & Gamis Shaliha & Edit | Hapus \\
\hline Profil Toko Online & 2 & Gamis Cahaya Sunnah & Edit: I Hapus \\
\hline Cara Beli & 3 & Gamis Khaula jaguar & Edit I Hapus \\
\hline Info Rekenina Toko & 4 & Gamis Jetblack Al-Khatib & Edit I Hapus \\
\hline 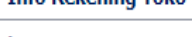 & 5 & Gamis set Jiblab Klok & Edit I Hapus \\
\hline Laporan & 6 & Gamis Faza Embos & Edit I Hapous \\
\hline Logout & & & \\
\hline
\end{tabular}

\section{Gambar 13. Tampilan Menu Data}

\section{Kategori Produk}

Pada penjelasan gambar diatas pada tampilan menudata kategori produk di atas terlihat dua item yang sudah diisi oleh admin yaitu nama kategori dan aksi (edit dan hapus).Tampilan menu data kategori produk ini administrator dapat 
mengedit dan menghapus data kategori produk.

\section{Tampilan Menu Data Produk}

Berikut adalah tampilan form data kategori produk.

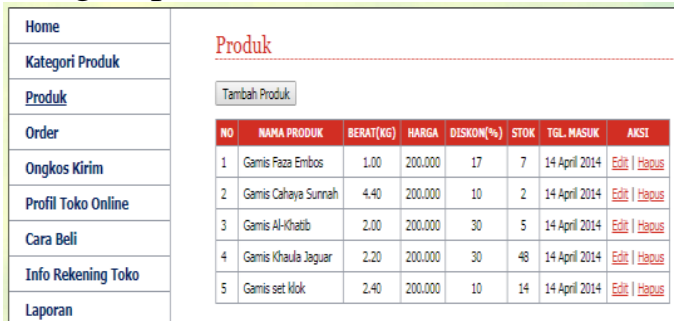

Gambar . 14 Tampilan Menu Data Produk

Pada tampilan menuproduk di atas terlihat tujuh item yang sudah diisi oleh admin yaitu nama produk, berat $(\mathrm{kg})$, harga, diskon, stok, tanggal masuk dan aksi (edit dan hapus).

\section{Tampilan Menu Data Order}

Berikut adalah form tampilan menu data order.

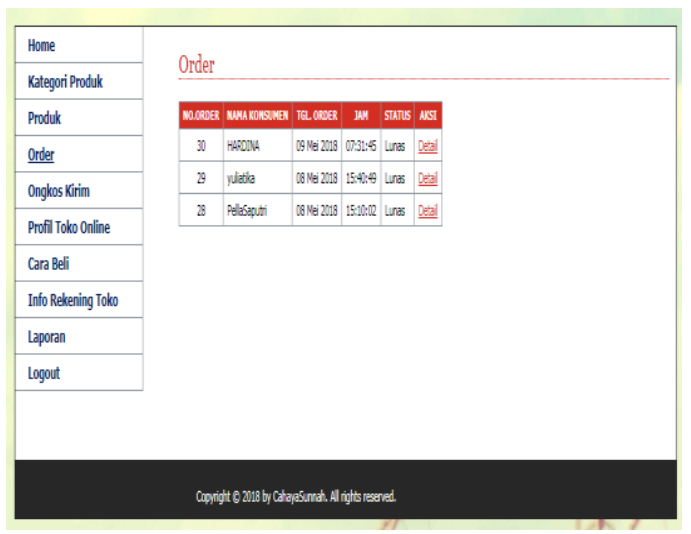

Gambar . 15 Tampilan Menu DataOrder

Pada tampilan menudata order di atas terlihat enam item yang sudah diisi oleh admin yaitu nomor order, nama konsumen, tanggal order, jam, status, aksi ( detail).
Tampilan Data Ongkos Kirim

Berikut adalah tampilan form data ongkos kirim.

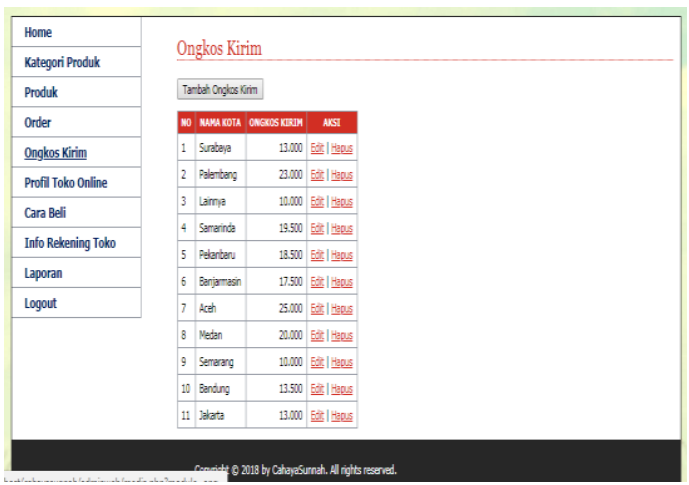

Gambar. 16 Tampilan Menu Data Ongkos Kirim

Pada tampilan menudata ongkos kirim di atas terlihat tiga item yang sudah diisi oleh admin yaitu nama kota, ongkos kirim, aksi (edit da hapus).

\section{Tampilan Menu Penjelasan CRM \\ Berikut adalah tampilan form penjelasan tentang Customer Relationship Management (CRM).

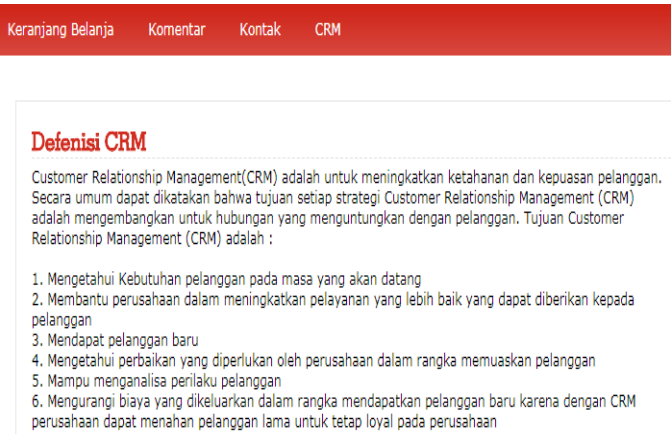

Kerangka komponen CRM diklasifikasikan menjadi tiga bagian: 1. Operational Customer Relationship management (CRM) dikenal sebagai front office perushhaan, salah satu peneraan CRM yang termasuk dalam kategori operasional CRM adalah dalam bentuk aplikasi web. Melalui web, suatu perusahaan dapat memberikan pelayanan kepada pelanggan.

\section{Gambar. 17 Tampilan Menu Penjelasan CRM}

Pada tampilan menu penjelasan Customer Relationship Management (CRM) akan terlihat menu-menu yang termasuk dalam CRM yaitu menu order (pelanggan loyal), menu produk (harga 
dan diskon), menu komentar dan menu produk terlaris.

\section{Tampilan Menu Laporan}

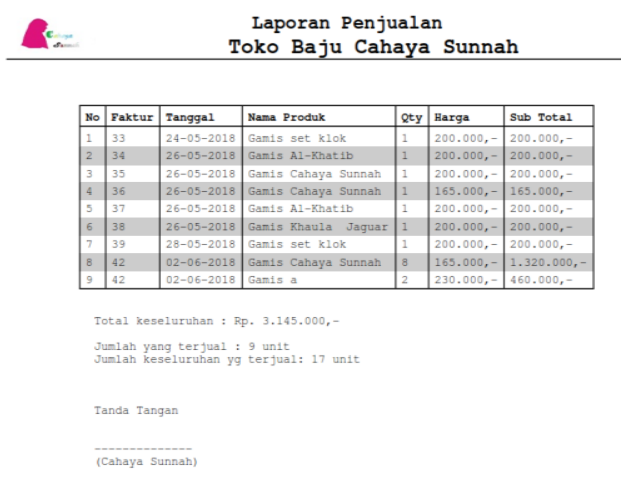

Gambar. 18 Tampilan Menu Laporan

Pada tampilan menu laporan telihat 2 gambar dimana pada gambar pertama merupakan gambar laporan per periode yang terdapat dua item yang akan diiisi oleh admin yaitu dari tanggal konsumen pertama mulai membeli produk dan sampai dengan tanggal akhir konsumen membeli produk kemudian proses. Pada gambar kedua terlihat gambar output laporan penjualam per periode yang sebelumnya sudah diisi oleh admin dan memilih tombol proses.

\section{SIMPULAN}

Berdasarkan hasil penelitian dan pembahasan, maka kesimpulan yang dapat diambil dari penelitian ini adalah sebagai berikut :

1. Dengan menggunakan sistem terkomputerisasi menggunakan metode Customer Relationship Management (CRM) Sistem informasi berbasis web maka proses penyimpanan data dapat lebih akurat dan tersimpan rapi dan pembuatan laporan penjualan akan cepat dan tepat waktu.

2. Dengan menggunakan metode Customer Relationship Management (CRM) untuk pelayanan transaksi secara online membuat hubungan perusahaan dan konsumen lebih dekat sehingga membuat konsumen loyal dan tidak ingin beralih ke toko lain. sedangkan dalam penyampaian informasi promosi akan lebih cepat dan respon terhadap penjualan pun akan lebih cepat.

3. Sistem informasi berbasis web dengan metode Customer Relationship Management (CRM) dapat memberikan informasi terbaru produk, sistem informasi berbasis web dengan metode Customer Relationship Management (CRM) yang diusulkan adalah sistem yang telah memenuhi kebutuhan dan mempunyai keunggulan yaitu terintegrasi dengan sistem yang bekaitan dengan sistem informasi pemasaran.

\section{DAFTAR PUSTAKA}

Aisyah, D. A., \& Falgenti, K. (2017). Sistem Informasi Penjualan Berbasis Kinerja pada Proyek Apartemen Mega City Bekasi. Jurnal Teknologi dan Sistem Informasi 3(3), 343-352

Bayu, K. A. (2017). Sistem Informasi Pemasaran Jaket dengan Penerapan Customer Relationship Management (Crm) Berbasis Web.Skripsi. Universitas Nusantara PGRI Kediri

Hendrianto, D. E. (2014). Pembuatan Sistem Informasi Perpustakaan Berbasis Website pada Sekolah Menegah Pertama Negeri 1 Donorojo Kabupaten Pacitan. IJNS Indonesian Journal on Networking and Security, 3(4), 57-64

Sugesti, E. (2018). Pengaruh Sistem Informasi Pemasaran dan Strategi Penjualan terhadap Persaingan Penjualan Produk PT. Bank Agris, 
2019. Intecoms: Journal of Information Technology and Computer Science 2 (1): 1-9

tbk Medan. Jurnal Riset

Manajemen \& Bisnis (JRMB), 3(2), 21-27

Mardison, M., \& Pramudia, A. (2015).

Perancangan dan Pembuatan

Aplikasi Customer Relationship

Management pada Koperasi

Pembangunan Usaha Sumbar

Berbasis Web. Jurnal

KomTekInfo Fakultas Ilmu

Komputer, 2(1), 6-9

Madcoms, M. (2015). Kupas Tuntas

Pemrograman PHP \& MySQL dengan Adobe Dreamweaver CC. Yogyakarta: Andi

Ovi, D., Afrina, M., \& Ibrahim, A. (2012). Penerapan Customer Relationship Management (CRM) Berbasis Web (Studi Kasus Pada Sistem Informasi Pemasaran di Toko YEN-YEN). Jurnal Sistem Informasi, 4(2), 516-529

Pressman, R. S. (2010), Software Engineering: a practitioner's approach, McGraw-Hill, New York 